\title{
The sexist nature of sexual expressions in Afrikaans'
}

\author{
Gerhard B. van Huyssteen \\ Department of Afrikaans and Dutch \\ Potchefstroom University for CHE \\ POTCHEFSTROOM
}

\begin{abstract}
The sexist nature of sexual expressions in Afrikaans

Cognitive metaphor theories indicate that sexual metaphors are metaphors in which a taboo domain of knowledge is described in terms of a non-taboo domain of knowledge. Data from the Afrikaans language substantiate the idea that mappings between these two domains are motivated on cognitive as well as on pragmatic grounds. In this article, it will be attempted to indicate how sexism is sustained by sexual metaphors in the Afrikaansspeaking community. The fact that sexism is underlaid by sex role stereotypes, leads to the conclusion that sexism is also sustained by means of the use of metaphors. The fact that different metaphors exist in different subculture groups indicates that metaphorical mappings are strongly influenced by culture and ideology. Data from feminist communities substantiate this assumption. Finally, the possibility of metaphor transformation as a mechanism of purification with regard to sexism and stereotyping is investigated.
\end{abstract}

\section{Introduction}

A point of departure in cognitive linguistics is that human beings have - as part of their rational nature - the need to understand and describe their existence and the world around them. Furthermore, it is believed that people interpret and describe their experiences by means of a process of categorisation.

This article focuses on the way in which cognitive mechanisms, like metaphor and metonymy, contribute to this categorisation process. The aim is to obtain answers to the following questions (based on Jackendoff, 1983:3):

1 This article is bascd on a Magister Artium, completed at the University of Pretoria, Pretoria, South Africa I wish to acknowledgc and thank Prof. Adclia Carstens for numerous contributions to the obtaining of the degrec, and in the writing of this article. I would also like to thank Caitlin Hines, George Lakoff, Ivo Sanchez and Sarah Taub for useful comments during the 1995 LSA Summer Instutute in Albuquerque (New Mcrico, USA) 
- What is the nature of natural language that enables a person to talk about perceptions and experiences?

- What conclusions about conceptualisation and categorisation could be drawn from the grammatical and lexical structure of natural language?

The linguistic data focused on are sexual expressions in Afrikaans ${ }^{2}$. The notion sexual expressions, refers to lexicalised theoretical linguistic units (lexemes, sentence phrases, clauses, sentences) and pragmatical linguistic units (expressions, nonce formations, etc.) which refer to aspects of the sexual domain. This collective body of lexical items could be referred to as the sexual lexicon.

\section{Categorisation}

The development of Prototype Theory in the seventies (see amongst others Rosch, 1978) perceived categorisation as a sub-discipline of Psychology. However, the work of Rosch not only had implications for Psychological theories, but also played an important role in the development of linguistic theories.

It was especially the language philosophers George Lakoff and Mark Johnson who applied the principles of the Prototype Theory to linguistic categories:

... it is important to see that prototype effects occur not only in nonlinguistic conceptual structure, but in linguistic structure as well. The reason is that linguistic structure makes use of general cognitive apparatus, such as category structure. Linguistic categories are kinds of cognitive categories (Lakoff, 1987:57).

\subsection{Idealised Cognitive Models}

Lakoff (1987) describes the conceptual structures of human thought as Idealised Cognitive Models (ICM's). Cognitive models are mental structures directly embedded in bodily experience (whether personal, empirical or collective). If not directly linked, they are linked to models based on bodily experience (Johnson, 1987:41; Lakoff, 1987:13).

2 Data were collected at the University of Pretoria, Pretoria, South Africa. by means of personal interviews and the recording of everyday conversations The subjects were mainly heteroscxual male and femalc students. The focus of rescarch was mainly directed to the sex act, male and female genitalia, as well as on other aspects in the sexual domain (like foreplay, masturbation. group sex, etc) 
Considering that ICM's enable one to define concepts that are either not logical or not directly representative of reality, they provide the opportunity for perceptions embedded in the cognitive experience of the observer. To illustrate: when a man with no sexual experience refers to female genitalia as a koek (cake), pastei (pie) or oester (oyster), he defines it in terms of the general cognitive metaphor that suggests that female genitalia are edible objects. The cognitive structuring is based neither on the experience of the speaker nor on reality, but is rather derived from the collective realm of experience of which the speaker is part.

In this article, the stance is taken that the primary function of metaphor and metonymy is to transform more abstract domains into concepts that are easier to understand. Metaphor and metonymy are thus perceived as mechanisms in the cognitive process, rather than ICM's: "Propositional and image-schematic models characterize structure; metaphoric and metonymic models characterize mappings that make use of structural models" (Lakoff, 1987:154).

Taylor $(1989: 124,134)$ perceives metaphor and metonymy as two of the most basic meaning-extension processes. In an attempt to define a vaguely structured concept, metaphoric and metonymic mappings are made between two different domains. These mappings are eventually realised in linguistic expressions. This article focuses mainly on metaphorical mappings in the sexual domain.

\subsection{Metaphors}

In cognitive metaphor theories (like that of Lakoff \& Johnson, 1980), metaphor is perceived as a basic cognitive process by which a difficult, complex, abstract or unknown domain of knowledge (the so-called target domain) is interpreted or understood in terms of a less complex, more concrete or better known domain of knowledge (the so-called source domain).

When aspects of sexuality are named, it often happens that the taboo domain is interpreted and described in terms of a non-taboo domain, because the terms of the non-taboo domain are probably socially more acceptable (or unmarked) than those of the taboo domain (see Diagram l).

A person who wants to refer to female genitalia (the taboo target domain), will, for example, draw on common properties from a non-taboo source domain (the domain of edible objects). It could also be that the source domain is visually more prominent than the target domain, which often represents the internal bodily physiology of a person. Female genitalia are, for example, relatively unobstrusive, and are therefore referred to in terms of a source domain that is visually stronger defined (examples like toegerankte-middeldeur-heerlikheid (overgrown divided deliciousness), klapperhaartrekpleister (coir plaster), 
vertikale-glimlag-met-wolwange (vertical smile with woollen cheeks) are visually descriptive of female genitalia).

\section{Diagram 1: Taboo domain and non-taboo domain}

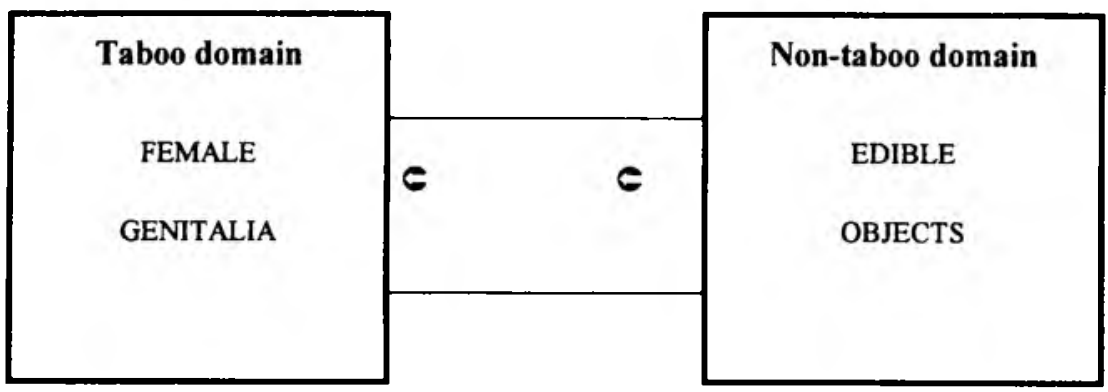

Meaning extension can occur due to mappings between two different domains of knowledgde that share certain ontological properties on a generic level. These mappings can only be realised if the target and source domain share enough properties. Indurkhya (1992:64) confirms this assumption:

... juxtaposing any random domain may not result in any creation of similarity, and even when it does, the created similarities may not be particularly insightful ones, and even when they are, the insights may not be helpful in solving a certain problem with the target domain.

With regard to sexual expressions, mainly two kinds of metaphorical mappings between the source and the target domain can be distinguished, namely similaritycreating metaphors and similarity-based metaphors (Indurkhya, 1992). When similarities are created between the target and source domain due to the amount of transposed epistemological knowledge in similarity-creating metaphors, there are already, to a certain extent, ontological similarities between the target and source domain in similarity-based metaphors. These ontological similarities do not, however, imply that similarities are not also created during this process. This phenomenon can be explicated by means of reference to sexual expressions.

In similarity-based metaphors for sex, like steek (stab), stoot (push), spring (jump), dek (serve - a cow) and pomp (pump), there are already, on a generic level, certain similarities between the action of sex and the actions which are 
understood by the conventional meanings of these words. Consider the following diagram for naai (sew, stitch - sex) ${ }^{3}$.

\section{Diagram 2: $\quad$ Similarity-based metaphors}

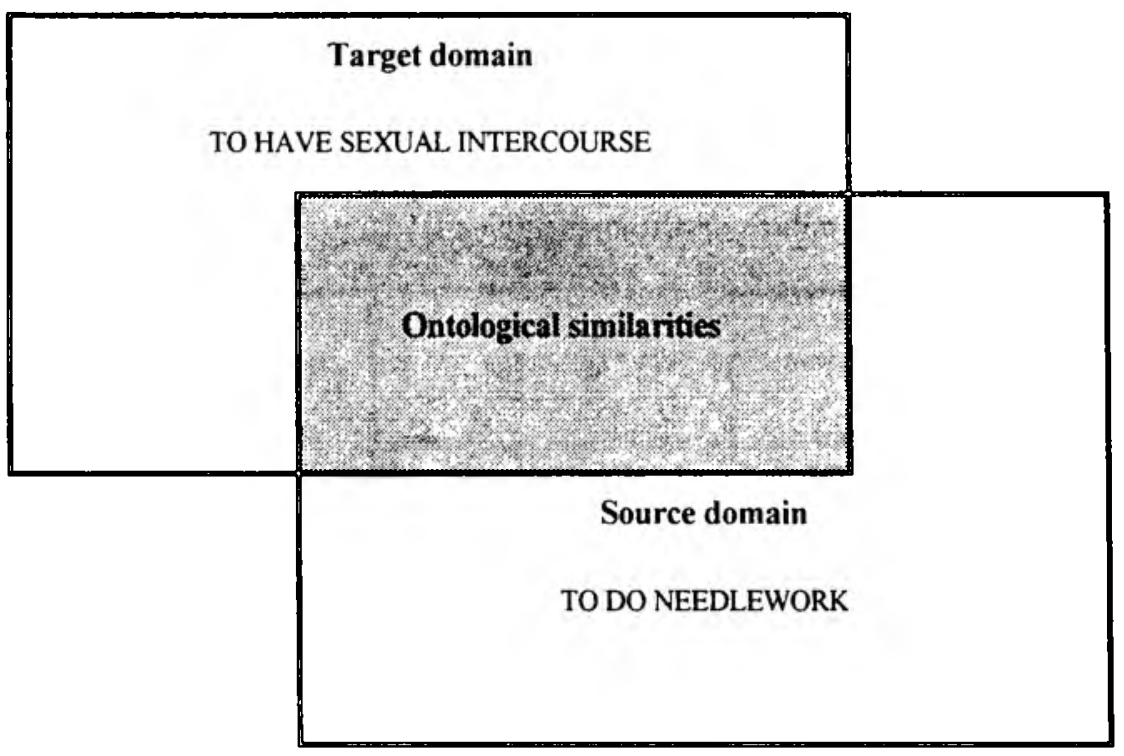

The shaded area of this diagram indicates the ontological similarities between the sexual act (the target domain) and the act of stitching with a sewing-machine (the source domain): both acts have the default values [+ iterative], [+ up and down motion] and [+ penetration]. The semantic category is thus extended by superimposing existing qualities of the source domain (as perceived by men) on the target domain.

These projections are often associated with sensory perception: the target domain looks/smells/tastes/sounds/feels like the source domain. Much of the sexual expressions can be seen as similarity-based metaphors. Consider mielie (corn-cob - penis), piesang (banana - penis), wors (sausage - penis), pistool (pistol - penis), slymsloot (slime ditch - female genitalia), vis (fish - female genitalia), enkelgleufbeursie (single compartment purse - female genitalia), riemruk (thong jerking - male masturbation), horing (horn - erection), klokke

3 The literal translation of the Afrikaans expression is offered first, followed by the extended mcaning 
(bells - testicles), eiers (eggs - testicles), etc. It is thus especially the structural attribute of the one domain that is projected onto the other domain (Lakoff $\&$ Turner, 1989:90): the penis has a similar physical shape as a corn-cob/ banana/sausage; the female genitalia smell like fish, etc.

With similarity-creating metaphors, new similarities are created between two domains which share no previous similarities. The transference of some ontological qualities from the one domain to the other creates, to a certain extent, new meaning within that domain, as the following diagram illustrates:

\section{Diagram 3: $\quad$ Similarity-creating metaphors}

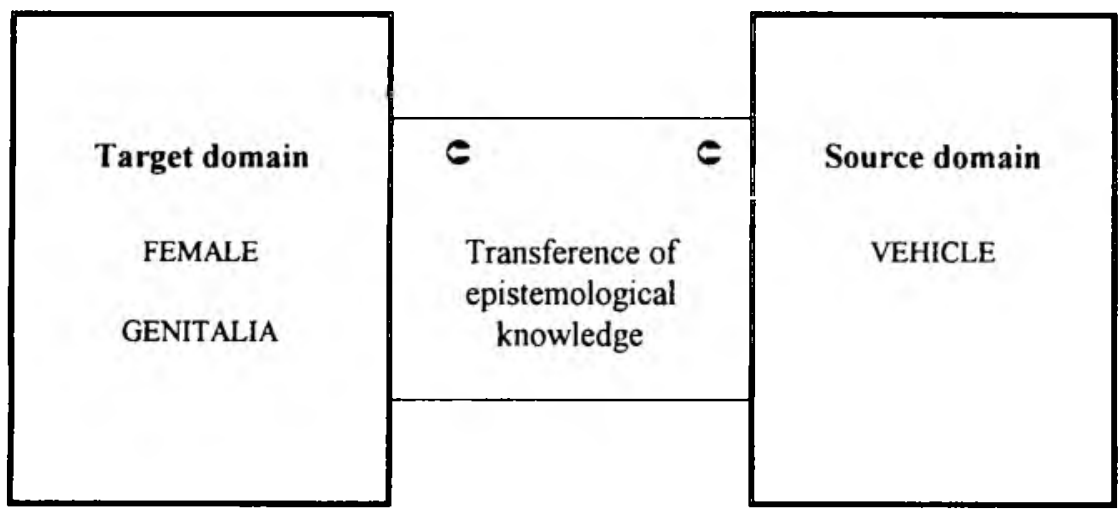

In the conceptual metaphor THE FEMALE GENITALIA ARE A VEHICLE, new qualities (which are neither intrinsic nor conventional) are transferred to the target domain - e.g. in expressions like wa (wagon - female genitalia), skoeter (scooter - female genitalia) and vleiswa-met-wolwiele (meat wagon with woollen wheels female genitalia). In these examples, the vagina is not only seen as a CONTAINER, but other correspondences are also mapped: the male, for example, is the driver who is taken somewhere - e.g. sy het hom laat kom (she let him come - she brought him to a climax). Once reaching this point, it is said that the male "came". The process leading to the male arriving at his destination, is often described in terms of the VEHICLE-metaphor - e.g. ry (drive - to have sexual intercourse). To get married is even considered as legalising sexual intercourse: hy het nou sy bestuurderslisensie (he's got his driver's license - he is married and is permitted to have sexual intercourse). Mappings such as these can be motivated on account of the general categorisation and conceptualisation processes of the human mind. 
Many examples of similarity-creating metaphors have already been recorded: voël (bird - penis), meneer (mister - penis), leeu (lion - female genitalia), koek (cake - female genitalia), pastei (pie - female genitalia), vrug (fruit - female genitalia), wiks (beat/smack - to have sexual intercourse), pakgee (give a hiding to have sexual intercourse), uithelp (to assist as a favour - to have sexual intercourse), etc. Considering the structural attributes of the female genitalia and a pie, for example, no obvious similarities exist. New similarities are created by means of metaphorical projection: the female genitalia are perceived as an edible object.

The distinction between similarity-creating and similarity-based metaphors must, however, not be seen as absolute. The projections between the two domains may sometimes be similarity-based as well as similarity-creating. Consider for example, guava (guava - female genitalia) being underlaid by two conceptual metaphors, namely: THE FEMALE GENITALIA LOOK LIKE A GUAVA (similaritybased metaphor) and THE FEMALE GENITALIA ARE AN EDIBLE FRUIT (similarity-creating metaphor).

In the similarity-based metaphor THE FEMALE GENITALIA LOOK LIKE A GUAVA, it is the pinkish colour, texture and form of a guava that are mapped onto the female genitalia; because the mappings are based on some existing similarities between the two domains, it is therefore seen as a similarity-based metaphor. Considering that the female genitalia are not edible in the general sense of the word, new attributes are created and mapped onto the domain of FEMALE GENITALIA. It can therefore also be considered as a similarity-creating metaphor.

Within certain syntactic-pragmatic contexts, it would be possible to ascertain whether the similarity-based or similarity-creating metaphor is activated. In the expression: Hy het haar bygekom met sy kierie (He got at her with his walkingstick - He had sex with her), the similarity-creating metaphor: THE PENIS IS A WHIPPING INSTRUMENT, would probably be activated, rather than: THE PENIS LOOKS LIKE A WALKING-STICK. In the expression: Hoe kan iemand seks hê met so 'n krom kierie? (How can somebody have sex with such a curved walking-stick? - How can somebody, with a curved penis like that, have sex?), the appearance of a walking-stick is mapped onto the appearance of a penis, rather than on some other functional attribute; therefore THE PENIS LOOKS LIKE A WALKING-STICK. Considering that vis (fish - female genitalia) is often used to express revulsion, the most active metaphor is probably the similarity-based metaphor THE FEMALE GENITALIA SMELL LIKE FISH.

The following sexual expressions for PENIS also have two underlying conceptual metaphors: 
Table 1: Similarity-based vs. similarity-creating metaphors

\begin{tabular}{|l|l|l|}
\hline Expression & Similarity-based metaphor & Similarity-creating metaphor \\
\hline $\begin{array}{l}\text { slang } \\
\text { (snake) }\end{array}$ & $\begin{array}{l}\text { THE PENIS LOOKS LIKE A } \\
\text { SNAKE }\end{array}$ & THE PENIS IS LIKE A SNAKE \\
\hline $\begin{array}{l}\text { piesang } \\
\text { (banana) }\end{array}$ & $\begin{array}{l}\text { THE PENIS LOOKS LIKE A } \\
\text { BANANA }\end{array}$ & THE PENIS IS LIKE A BANANA \\
\hline $\begin{array}{l}\text { sambok } \\
\text { (horsewhip) }\end{array}$ & $\begin{array}{l}\text { THE PENIS LOOKS LIKE A } \\
\text { HORSEWHIP }\end{array}$ & $\begin{array}{l}\text { THE PENIS IS LIKE A HORSE- } \\
\text { WHIP }\end{array}$ \\
\hline
\end{tabular}

To summarise: metaphorical mapping is a productive process within the sexual lexicon, where a taboo domain is often interpreted in terms of a non-taboo domain. Such mappings can be based on existing similarities, or can create new similarities.

\section{Conceptualisation and stereotyping}

The second question (based on Jackendoff, 1983:3) will be addressed next:

- What conclusions about conceptualisation and categorisation could be drawn from the grammatical and lexical structure of natural language?

Certain conclusions can be drawn about the structure of the cognitive categorisation and conceptualisation processes as realised in natural language usage. Lakoff and Johnson (1980:22) indicate that the most fundamental values in a certain culture will correspond with the most fundamental concepts in that culture. An analysis of the underlying metaphors in a culture could on the one hand serve as a basis for an analysis of the specific cultural values, but could also serve as a means to distinguish and identify certain cultural subgroups (Swanepoel \& Schreuder, 1991:31).

This article focuses specifically on metaphorical projections and how such structures establish certain stereotypes in male student groups at the University of Pretoria, South Africa. It will also be indicated how these stereotypes differ from those of certain female students at the same University.

\subsection{Sex stereotypes and language sexism}

Lakoff and Johnson's (1980) theory of categorisation corresponds with Kohlberg's (1966), which points out that the creation of stereotypes represents a 
process of "generalising" categorisation - all the members of a certain group are categorised according to the real or assumed characteristics of a specific subgroup.

According to Safarjan (1980:31-33), Kohlberg's cognitive-development hypothesis is the only developmental theory which focuses on the creation of sex stereotypes. Sex stereotyping is regarded as:

... an adaptive cognitive mechanism for partitioning or ordering wide diversity in social or physical objects into a relatively small number of large and internally similar classes. The sex stereotypes thus have their roots in early cognitive development (Safarjan, 1980:31-32).

Although Kohlberg estimates the socio-cultural influence on the creation of these sex stereotypes as minimal, the theories of Lakoff and Johnson indicate that such influence does play a certain role. Considering that the creation of sex stereotypes is based on the child's perception of his/her immediate environment, the social order and cultural conventions within a specific community would necessarily influence the development of stereotypes. A child who is raised in a home where the wife and mother occupies an inferior and subservient role, would probably regard the prototypical woman as inferior, submissive and subservient.

Lakoff (1987) pays much attention to social stereotypes. He indicates that social stereotypes are examples of metonymy where a subcategory represents the category as a whole in order to allow for snap decisions. When, for instance, a man says: Piet is by sy stoot (where stoot means push - Piet is with his girlfriend), the girl is being stereotyped in terms of her function as a sexual object by means of metonymic transference. As social stereotypes define cultural expectations and create prototypical characteristics, they are often used to make general conclusions (Lakoff, 1987:85).

Considering that sex stereotypes attribute to individual specific psychological characteristics and behavioural patterns with regard to sex (e.g. WOMEN ARE WEAK and WOMEN ARE INTELLECTUALLY INFERIOR), they lead to generalisations. Such generalisations could (and do) furthermore, lead to discrimination against the individual on account of his/her sex - a phenomenon known as sexism.

Spender (1980:30) points out that it has been proven that sexism in language is a reflection of sexism in the social environment and that a language will not change unless the social nonms are changed.

An analysis of sexual metaphors in a specific subculture (in this case, a group of Afrikaans-speaking male students at the University of Pretoria) would indicate 
that language expresses the attitudes, expectations and values of that specific subculture.

Table 2: Sexual intercourse (metaphorical projections)

\begin{tabular}{|c|}
\hline Generic conceptual metaphor \\
\hline AN ACT IS A TRADE \\
\hline Basic level conceptual metaphor \\
\hline SEXUAL INTERCOURSE IS LIKE FARMING \\
\hline Basic level conceptual metophor \\
\hline TO HAVE SEXUAL INTERCOURSE, IS TO PLOUGH \\
\hline Metaphoric linguistic expressions \\
\hline $\begin{array}{c}\text { bewerk (cultivate - sexual intercourse) } \\
\text { ploeg diep en saai op die walle (plough deep and sow on the banks - coitus } \\
\text { interruptus) } \\
\text { morge en morge ongeploegde vars plaaspoes (morgens and morgens of } \\
\text { unploughed fresh farm pussy - virgins) } \\
\text { you hit the red soil - sex with a black woman) }\end{array}$ \\
\hline
\end{tabular}

An analysis of "male" metaphors for the sexual act could serve as a basis to substantiate the above-mentioned statement. Compare the expressions in Table 2 which are based on the ICM: TO HAVE SEXUAL INTERCOURSE IS TO PLOUGH.

To plough is a traditional male activity which is associated with farming. Farming, as such, could be regarded as an industry (in Western cultures) which is traditionally dominated by males, producing stereotypes which could serve as sources of male chauvinism. When ploughing, the soil (which is often associated with the female - compare "Mother Earth") is in fact manipulated by the male, who tills and uses it. Traditionally, it is also regarded as the male's duty to till the soil (compare the Biblical prescription/condition in Genesis 3:17-19) 
Someone who experiences "coitus interruptus" for the first time, would, for instance, depend on his/her bodily experience, which corresponds to the mentioned phenomenon. As the male stereotypically regards the female as a piece of soil to be tilled, he would be inclined to use an expression such as ploeg diep en saai op die walle (plough deep and sow on the banks - coitus interruptus). This expression is based on the male's experience that to plough and then to sow the seed next to the furrow, would be a futile and sterile action. The speaker would not necessarily have physical experience within the agricultural industry, but could depend on collective knowledge and conventional images.

These mappings are explicated in the following diagram:

Diagram 4: TO HAVE SEXUAL INTERCOURSE IS TO PLOUGH (Mappings)

\begin{tabular}{|c|c|}
\hline Source domain & Target domain \\
\hline PLOUGHING & SEX \\
\hline Eartl/soil & Female genitalia \\
Plough (noun) & Penis \\
Plough (verb) & Sexual intercourse \\
Ploughers & Men \\
\hline
\end{tabular}

De Stadler (1992:132) indicates that semantic role prototypes reflect a person's experience as an active being (who experiences the world around him/her and can manipulate objects in this world). Within the framework of role semantics, an analysis of the above-mentioned expressions distinguishes between "the male as an agent/activator" and "the female as a patient/the one who (passively) experiences". Several metaphorical expressions for the sexual act clearly support this stereotypical attribution of roles, and also suggest that stereotyping can in some instances, be attributed to clearly defined cognitive schemas among men (in this case a subgroup of men).

These examples support the perception that the female body is an object which can be manipulated by the male. The male is always depicted as the active party during the sexual act, the one who controls the situation - compare spring (jump), dek (serve) and vasle (pin down). Several expressions suggest painful implications for the female - compare steek (stab), stamp (bump), brand (burn), spyker (nail), saag (saw), as well as pakgee (beat), naai (stitch), skrop (scrub) and omloop (run over). Regardless of these negative implications, the male is 
still regarded as the person who does the female a favour - compare uithelp (to assist as a favour).

Table 3: Sex stereotypes (Sexual intercourse)

\begin{tabular}{|c|}
\hline Sex stereotype \\
\hline WOMEN ARE PASSIVE, LIFELESS COMMODITIES \\
\hline \\
\hline Generic conceptual metaphor \\
\hline BODY PARTS ARE LIFELESS OBJECTS \\
\hline Basic level conceptual metaphor \\
\hline THE FEMALE GENITALIA ARE A PIECE OF WOOD \\
\hline Basic level conceptual metaphor \\
\hline MO HAVE SEXUAL INTERCOURSE IS LIKE DOING CARPENTRY \\
\hline Metaphorical linguistic expressions \\
\hline $\begin{array}{l}\text { Saag (saw) } \\
\text { Spyker (nail) } \\
\text { Brand (burn) }\end{array}$ \\
\hline
\end{tabular}

The penis is often metaphorically represented as an instrument which is directly and causally involved in the action (compare for instance pistool (pistol), roede (whip), spies (spear) and sambok (horse-whip)), while the female genitalia are regarded as a passive commodity (such as doos (box), enkelgleufbeursie (single compartment purse), koek (cake), etc.). From the above-mentioned analyses and examples it seems as if a female and female genitalia are usually attributed with the roles of patients who are not directly involved in the action.

From an analysis of sexual metaphors concerming the male sexual organs, it usually seems as if men and the male sexual organs semantically fulfil the roles of 
agents or instruments and are thus causally involved. From these deductions, the following metaphorical stereotypes would probably exist as male perceptions:

- A FEMALE IS A DISPOSABLE ENTITY/OBJECT

- A MALE IS A DANGEROUS INSTRUMENT

- A FEMALE IS A PASSIVE, LIFELESS COMMODITY

- A MALE is AN ACTIVE, LIVING CONSUMER

As the data have mainly been collected from a reasonably homogeneous subculture group (male students at the University of Pretoria), it could be expected that these stereotypes would be strongly evident in these societies.

This does not, however, imply that these perceptions exist in all communities. Other stereotypes ought to develop and exist in other subculture groups. Identifiable conceptual differences have been observed particularly in communities where feminism has had an important influence.

\subsection{Conceptual differences}

\subsubsection{Feminism}

Since the development and popularisation of feminism in the sixties, much has been written about the relationship between language and sex, and about forms of language sexism (compare, among others, Key, 1975; Lakoff, 1990; Miller \& Swift, 1977 and Thome \& Henley, 1975). In this article the hypothesis is postulated that feminism (as a socio-cultural movement) has a "corrective" influence on conceptual categorisation systems, in that it opposes social (and by implication also language) stereotyping.

The general assumption is that stereotypes are not easily changed, because they are embedded in social structures. As it is, in a certain sense, necessary to eradicate the existing cognitive structures, a strong input is required from the dominant culture to change stereotypes. This in turn, influences the realisation of language expressions, which influence the cognitive system, etc. This hypothesis correlates with the following statement by MacCormac (1985:157):

Metaphor is primarily a cognitive process originating in the creative process of juxtaposing referents found in the long-term memory and presenting them in linguistic forms. This linguistic presentation, however, changes culture by changing the ways in which we think about such things as scientific problems, human experience. and the educational process ... (A)s a creative cognitive device, metaphor may play a special role in an evolutionary epistemology 
By examining sexual expressions in male communities, one would probably be able to indicate that feminism has already had an influence in those communities, with regard to the stereotypes and perceptions about women. However, in the data examiner, the indication was clear that traditional stereotypes are still very active. Only one expression has been found which could possibly be an indication of feminist influence, that is leeu (lion - female genitalia). In this expression the stereotypical perception of the woman as an object has been exchanged for the ICM: THE FEMALE GENITALIA IRE A DANGEROUS ANIMAL. No other similar metaphors were noted in this specific student community - a phenomenon which can be an indication of the insignificant influence of feminism in this society.

Yet, there are areas in which the use of metaphors do indicate a change in stereotypes. In the language usage of outspoken feminists the tendency was observed that references to male sexual organs were consciously used as vocative and pejorative expressions. For instance, compare:

(1) Jou piel, wat maak jy? (You prick, what are you doing?)

(2) Daai ou is 'n regte voël! (That guy is a real prick!)

These vocative and pejorative expressions could be seen as a direct reaction to the conventional pejorative use of lexical items which refer to aspects of female genitalia. In literature, the use of creative metaphors is a natural and common technique. One would thus expect to find new linguistic metaphors and even new conceptual metaphors in literary works.

The following examples from the work of Andre P. Brink substantiate this hypothesis:

(3) "... die gulsige snawel wat my verorber het" (Brink, 1993:57) (the gluttonous beak that devoured me).

"Lateraan het ek hom weer gemelk ..." (Brink, 1982:17) (Later, I milked him again).

(5) “... sagte blare van die sluimerende roos ..." (Brink, 1967:114) (soft petals of the slumbering rose).

4 It should be noted that in Afrikaans men very rarely use references to male genitalia in vocative and pejorative cxpressions - they normally use references to female genitalia for this function (e.g. Jou kon!! - You cunt!) In English, on the other hand, reference to male and female genitalia occurs in epithets Allan (1990:165), however, indicates that in English, as in Afrikaans, the same imbalance occurs: "Terms of abuse invoking the female sex organ have a wider range than those involving the male sex organ" 
In (3) we find a striking reversal of a conventionalised expression While voel (bird - penis) usually refers to the male sexual organs, Brink reverses the metaphor in this phrase to refer to the female genitalia in tenns of the parts of a bird. In addition, the beak of the bird here represents an active agent which consumes the man/male. In (4) the female also becomes an active agent, while the male is being passively milked like a cow. Although a rose is a passive object which can be cut/picked by a man, Brink describes the female genitalia in (5) as something soft and precious. It is therefore not an ordinary commodity, but something which has to be nurtured an preserved by the male.

It seems apparent from the data that some authors of literary works 5 as well as outspoken feminists are making a concerted effort to change the sex stereotypes concerning women. By using novel metaphors which do not fit into the conventionalised pattern, new ICM's are created.

\subsection{Final remarks}

In this article it has been attempted to indicate that sexual metaphors in Afrikaans are cognitively motivated, and that this process often leads to stereotyping and generalisation. This phenomenon is, however, not only relevant to Afrikaans. Data in English (Aman, 1993) endorse the same sex stereotypes.

Similarity creating metaphors such as honey-pot (female genitalia), box (female genitalia), snackbar (female genitalia), treasure-box (female genitalia), fat rabbit (female genitalia), pecker (penis), banger (penis), godgiven groover (penis), love pump (penis), love sceptre (penis), as well as the large number of personal names used to refer to the penis (compare Charlie, Fred. Harvey. John, John Henry, John Thomas, Milton. Mr. Happy, Mr. Johnson. Oscar, Pedro, Percy, Pete, Peter, Rufus, Thomas Jefferson, Walter and Willie), confinn that the same tendency probably exists in English (Aman, 1993).

In the classic The Perfumed (Farden (Nefzawi, 1963), which had already been written before 1850, Arabic metaphors used for the penis, such as El mamama (the dove), Al ahlil (the liberator), El heurmak (the untameable), El zodamme (the

5 The following examples by female pocts also support this argument:
(1) tecr soos in oog/d, sag soos murg . (Eybers, 1982) (tender as an cyclid, soft $/$ as marrow ... - penis)
(2) waterdigte kompas (Hambidgc. 1987:42) (waterproof compass - female genitalia)
(3) jou fiksc vagina.. (Krog. 1989:95) (rour fit vagina) 
crowbar), El dekhal (the intruder/thief) and the vagina such as $E l$ sakout (the quiet one), El taleb (the longing one), El moudd (the accommodating one), El moudine (the assistant) and El sabeur (the retired one), also confirn this phenomenon.

It would thus be interesting to conduct similar research in communities where men do not play the dominant sex role. It could be expected that the cognitive schemes in these communities would be responsible for alternative sexual metaphors, such as the influence of feminism has already indicated in Afrikaans.

\section{Bibliography}

Aman, R. (ed.) 1993. Talking dirty. London : Robson Books.

Allan, K. 1990. Some English terms of insult invoking sex organs - evidence of a pragmatic driver for semantics. In: Tsohatzidis, S.L. (ed.) Meanings and prototypes. London Routledge. p. 159-194.

Brink, A.P. 1967. Miskien nooit. Kaapstad : Human \& Rousseau.

Brink, A.P 1982. Houd-den-Bek. Emmerentia : Taurus.

Brink, A.P. 1993. Imeendeel. Kaapstad : Human \& Rousseau

De Stadler, L.G. 1992. Semantiese rolle en die polisemiese waardes van werkwoorde. South African Journal for Linguistics, 10(3):131-139.

Eybers, E. 1982. Gedigte 1936-1958. Kaapstad : Tafelberg

Hambidge, J. 1987. Die anatomie van melancholie. Kaapstad : Human \& Rousseau.

Indurkhya, B. 1992. Metaphor and cognition: an interactionist approach. Dordrecht Kluwer Academic Publishers.

Jackendoff, R. 1983. Semantics and cognition. Cambridge : The MIT Press.

Johnson, M. 1987. The body in the mind. Chicago : University of Chicago Press

Key, MR 1975. Male/Female language. Metuchen : Scarecrow Press.

Kohlberg, L. 1966. A cognitive-developmental analysis of children's sex-role concepts and attitudes. In: Maccoby, E.E. (ed.) The development of sex differences Stanford Stanford University Press. p. 82-172.

Krog, A. 1989. Lady Ame Bramley: Taurus.

Lakoff, G. 1987 Women, fire, and dangerons things Chicago : University of Chicago Press.

Lakoff, G. \& Johnson, M. 1980. Metaphors we live by. Chicago : University of Chicago Press.

Lakoff, G. \& Turner, M. 1989. More than cool reason Chicago : University of Chicago Press.

Lakoff, R.T 1990 Talking power: The politics of language. New York : Basic Books.

Mac Cormac, ER 1985. A cognitive theory of metaphor Cambridge : The MIT Press

Miller, C \& Swift, K 1977. Words and women. New York Doubleday

Nefzawi, S. 1963 The perfumed garden Translated by Sir Richard Burton (1886) London : Granada

Rosch, E. 1978. Principles of categorization In: Rosch, E \& Lloyd, B.B. (eds.) Cogmtion and categorization. Hillsdale : Lawrence Erlbaum Associates. p. 27-48.

Safarjan. P T 1980 Sex stereotypes as natural language categorıs Ann Arbor University Microfilm International

Spender, D 1980. Man made language London: Routledge \& Kegan Paul 
Swanepoel, P H \& Schreuder, S E.M 1991 Metaforiek, retonek en politieke beriggewing Commumicatio, 17(1) 7-34

Taylor, J.R 1989 Lingmisfic categorization Oxford Clarendon Press

Thorne, B \& Henley, N (eds) 1975. Langwage and sex Differences and donmance. Rowley Newberry House 
